\title{
Wide dynamic range of surface-plasmon-resonance-based assay for hepatitis B surface antigen antibody optimal detection in comparison with ELISA
}

\begin{abstract}
Limit of detection (LOD), limit of quantification, and the dynamic range of detection of hepatitis B surface antigen antibody (anti-HBs) using a surface plasmon resonance (SPR) chip-based approach with Pichia pastoris-derived recombinant hepatitis B surface antigen (HBsAg) as recognition element were established through the scouting for optimal conditions for the improvement of immobilization efficiency and in the use of optimal regeneration buffer. Recombinant HBsAg was immobilized onto the sensor surface of a CM5 chip at a concentration of $150 \mathrm{mg} / \mathrm{L}$ in sodium acetate buffer at $\mathrm{pH} 4$ with added $0.6 \%$ Triton X-100. A regeneration solution of $20 \mathrm{mM} \mathrm{HCl}$ was optimally found to effectively unbind analytes from the ligand, thus allowing for multiple screening cycles. A dynamic range of detection of $\sim 0.00098 і ̈ 0.25 \mathrm{mg} / \mathrm{L}$ was obtained, and a sevenfold higher LOD, as well as a twofold increase in coefficient of variance of the replicated results, was shown as compared with enzyme-linked immunosorbent assay (ELISA). Evaluation of the assay for specificity showed no cross-reactivity with other antibodies tested. The ability of SPR chip-based assay and ELISA to detect anti-HBs in human serum was comparable, indicating that the SPR chipbased assay with its multiple screening capacity has greater advantage over ELISA.
\end{abstract}

Keyword: Anti-HBs; Chip-based detection assay; Hepatitis B surface antigen; Pichia pastoris; Surface plasmon resonance 